\title{
Cor pulmonale and silicosis: a necropsy based case-control study
}

\author{
J Murray, G Reid, D Kielkowski, M de Beer
}

\begin{abstract}
The presence of cor pulmonale at death in relation to other factors such as emphysema, silicosis, and thromboembolism was analysed in a case-control study of 732 South African gold miners. Marked emphysema was the highest risk factor with an odds ratio of $21 \cdot 32$ (95\% confidence interval $(95 \% \mathrm{CI}) 5 \cdot 02-90 \cdot 7)$, then extensive silicosis (OR 4.95, 95\% CI 2.92-8.38) and thromboembolic disease (OR $1 \cdot 92,95 \%$ CI 1.37-2.69). Age and smoking were not significant predictors of cor pulmonale.
\end{abstract}

(British fournal of Industrial Medicine 1993:50:544-548)

Cor pulmonale denotes right ventricular hypertrophy secondary to structural or functional abnormalities of the lungs. ${ }^{1}$ Right ventricular hypertrophy is a response to pulmonary arterial hypertension that may be the result of vasomotor narrowing of small pulmonary arteries and arterioles or anatomical obliteration of the vascular bed. ${ }^{2}$ Reliable estimates of the prevalence of cor pulmonale are sparse but it has been stated that, beyond the age of 50 cor pulmonale is the third most common cardiac disorder, after coronary and hypertensive heart disease. ${ }^{2}$

The most frequent cause of cor pulmonale in the general population is considered to be vasomotor increase in pulmonary vascular resistance as a result of alveolar hypoxia consequent on chronic obstructive lung disease-that is, chronic bronchitis, bronchiolitis, and emphysema. ${ }^{3}$ Although cigarette smoking is the most important environmental aetiological factor associated with chronic obstructive lung disease, ${ }^{4}$ occupational exposures are being increasingly implicated. ${ }^{5}$ Anatomical increase in the pulmonary vascular resistance may be due to

National Centre for Occupational Health, PO Box 4788, Johannesburg, 2000, South Africa

J Murray, G Reid, D Kielkowski

City Health Department, PO Box 1477, Johannesburg 2000

$M$ de Beer obliteration of the vascular bed by thromboembolic disease or fibrotic processes. Silicosis fits into this last group. In silicosis there is perivascular location of silica dust and fibrosis that results in obliteration of the terminal branches of the pulmonary vasculature $^{6}$ and forms a possible basis for the development of cor pulmonale.

The aim of this study was to determine the contribution of silicosis to the development of cor pulmonale.

\section{Methods}

\section{STUDY POPULATION}

The study population consisted of white South African gold miners aged 45 and over who underwent a full necropsy between 1974 and 1988 . Examination of the cardiorespiratory organs at necropsy is required by law for compensation purposes for all miners and ex-miners who die in South Africa provided the next of kin agrees. ${ }^{\top}$ Examination of the cardiorespiratory organs is performed by pathologists at the National Centre for Occupational Health and findings are recorded in a computerised data base known as PATHAUT (Pathology Automation). ${ }^{8}$ Full examination is offered for miners dying within $100 \mathrm{~km}$ of Johannesburg, in whom inflation of the lungs and dissection of the heart according to Fulton's technique $^{9}$ are routinely performed. After removal of fat and coronary vessels the atria are separated from the ventricles; the right ventricle (RV) and the left ventricle and the septum $(\mathrm{LV}+\mathrm{S})$ are weighed separately. For those dying further afield the necropsy is limited to the cardiorespiratory organs, which have been previously removed and preserved in formalin.

It is estimated that $86 \%$ of white South African gold miners who die undergo necropsy. ${ }^{10}$ There are no significant differences in age, years of service, and prevalence of pneumoconiosis between men undergoing full and limited necropsies; however, when compared with those who have no examination, those who have necropsy had longer service and had been compensated less often during life. ${ }^{10}$ This study was limited to those miners and exminers undergoing full necropsies. 
Table 1 Study population and exclusions

\begin{tabular}{lr}
\hline Initial population (full necropsy 1975-87) & 4226 \\
Excluded subjects: & 48 \\
Heart mass, RVM or LV + S missing & 1917 \\
LV + S > 224 g & 61 \\
Valve disease & 14 \\
Asbestosis & 2186 \\
Final study population & 391 \\
Selected cases & 341 \\
Selected controls & 1454 \\
Remainder did not meet criteria for cases and controls & \\
\hline
\end{tabular}

\section{SELECTION OF CASES AND CONTROLS}

The original criteria of Fulton et $a l^{9}$ for right ventricular hypertrophy were applied to define cases. A case was any person with a ratio of $\mathrm{LV}+\mathrm{S}: \mathrm{RV}>2: 1$ and a right ventricular mass $(\mathrm{RVM})>79 \mathrm{~g} ; \mathrm{LV}+\mathrm{S}$ was $<190 \mathrm{~g}$. The control subjects had normal hearts-that is, $(\mathrm{LV}+\mathrm{S}): \mathrm{RV}$ of $2 \cdot 3: 1$ to $3 \cdot 3: 1, \mathrm{RVM}<65 \mathrm{~g}$, TVM (total ventricular mass) $<250 \mathrm{~g}$, and LV $+\mathrm{S}<190 \mathrm{~g}$.

Because right ventricular hypertrophy may develop secondary to left ventricular hypertrophy, subjects with $\mathrm{LV}+\mathrm{S}>224 \mathrm{~g}$ were excluded from the study $(n=1917)$. Subjects were also excluded if any valvar abnormality was apparent $(n=61)$.

Ideally, all subjects with ischaemic heart disease should have been excluded. As most of the study population had this, the number of subjects remaining after exclusion would have been too small for analysis. The proportion of cases with ischaemic heart disease was similar to that of controls and the disease was thus effectively controlled for.

Table 1 shows the selection of the study population. In 48 subjects the weights of the hearts had not been recorded in the data base and these, together with a further 14 subjects with asbestosis, were excluded.

A total of 4226 miners and ex-miners died aged 45 and older and had full necropsies between 1974 and 1988. Of these, 2186 comprised the final population. One thousand four hundred and fifty four subjects were excluded on the basis of RVM between $64 \mathrm{~g}$ and $80 \mathrm{~g}, \mathrm{LV}+\mathrm{S}>189 \mathrm{~g}$, TVM $>249 \mathrm{~g}$, and $\mathrm{LV}+\mathrm{S}: \mathrm{RV}$ between $2: 1$ and $2 \cdot 3: 1>3 \cdot 3: 1$. These subjects were excluded because they did not fit the strict definitions of a case or control that were applied to ensure clear categories for analysis with no overlap of the characteristics of interest. Thus 391 cases and 341 controls were analysed.

\section{DEFINITIONS}

Ventricular hypertrophy

The ratio $\mathrm{LV}+\mathrm{S}: \mathrm{RV}$ provides the most appropriate method of assessing ventricular hypertrophy. A ratio of $\mathrm{LV}+\mathrm{S}: \mathrm{RV}<2: 1$ indicates indisputable right ventricular hypertrophy provided that left ventricular hypertrophy (defined as $\mathrm{LV}+\mathrm{S}>225 \mathrm{~g}$ ) is absent. ${ }^{9}$

\section{Ischaemic heart disease}

Ischaemic heart disease was classified as minimal disease - slight coronary artery atheroma; moderate disease-moderate coronary artery atheroma; and severe disease-pronounced atheroma, extensive myocardial fibrosis, or myocardial infarction.

\section{Silicosis}

Silicosis was assessed macroscopically and confirmed microscopically. It was graded as slight, moderate, or extensive, based on the profusion of nodules. Eleven subjects with massive fibrosis were included in the extensive disease category.

\section{Emphysema}

The lungs were inflated with $10 \%$ formalin at a pressure of $25 \mathrm{~cm} \mathrm{H}_{2} \mathrm{O}$ and a paper mounted whole lung Gough-Wentworth section ${ }^{11}$ was made from one lung (usually the right). Emphysema was assessed by a modification of the grid method with 20 radiating zones. The amount of emphysema in each zone was estimated on a scale of 0 to 5 , giving a possible total score of $100(5 \times 20)$. Emphysema was graded as insignificant $(<35)$, moderate (35-65), or marked (>65).

The presence of pulmonary thromboembolism was also recorded. Smoking histories were obtained from PATHAUT and subjects were grouped for analysis into smokers, ex-smokers, and those who had never smoked. Height and last live mass were also used in the description of the study population (table 2).

\section{Results}

Table 2 presents the demographic characteristics of the cases and controls. Controls were slightly younger and shorter and weighed less than the

Table 2 Demographic characteristics of cases and controls

\begin{tabular}{|c|c|c|c|c|c|}
\hline & \multicolumn{2}{|c|}{ Cases } & \multicolumn{2}{|c|}{ Controls } & plalia \\
\hline Age & \multirow{2}{*}{\multicolumn{2}{|c|}{$66 \cdot 0(45-88)$}} & \multirow{2}{*}{\multicolumn{2}{|c|}{$65 \cdot 6(45-94)$}} & \\
\hline$(y ;$ mean $($ range $))$ & & & & & 0.5325 \\
\hline $\begin{array}{l}\text { Body mass } \\
(\mathrm{kg} ; \text { mean (range) })\end{array}$ & \multicolumn{2}{|c|}{$70 \cdot 7(46-110)$} & \multicolumn{2}{|c|}{$69 \cdot 1(41-180)$} & 0.1109 \\
\hline $\begin{array}{l}\text { Height } \\
\quad(\mathrm{cm} \text {; mean (range)) }\end{array}$ & \multicolumn{2}{|c|}{$171.9(136-198)$} & \multicolumn{2}{|c|}{$170 \cdot 6(138-200)$} & 0.0178 \\
\hline \multicolumn{3}{|c|}{$\begin{array}{l}\text { Smoking state }\left(\text { No }\left({ }^{\circ} 0\right)\right)_{181} \\
\text { Smoker }\end{array}$} & & & \\
\hline Smoker & 181 & $46 \cdot 3$ & 163 & $47 \cdot 8$ & \\
\hline Ex-smoker & 89 & $22 \cdot 8$ & 65 & $19 \cdot 1$ & \\
\hline Non-smoker & 39 & $10 \cdot 0$ & 45 & $13 \cdot 2$ & \\
\hline Unknown & 82 & $21 \cdot 0$ & 68 & 19.9 & \\
\hline Total & 391 & & $3+1$ & & \\
\hline
\end{tabular}

$\chi^{2}=3.02, \mathrm{df}=3, \mathrm{p}=0.3891$ 
Table 3 Frequency of ischaemic heart disease

\begin{tabular}{lcccc}
\hline & Cases & \multicolumn{3}{c}{ Controls } \\
& No & $(\%)$ & \multicolumn{1}{c}{ No } & $(\%)$ \\
\hline Severe & 101 & $(25 \cdot 8)$ & 80 & $(23 \cdot 5)$ \\
Moderate & 19 & $(4 \cdot 9)$ & 31 & $(9 \cdot 1)$ \\
Minimal & 197 & $(50 \cdot 4)$ & 160 & $(46 \cdot 9)$ \\
None & 74 & $(18 \cdot 9)$ & 70 & $(20 \cdot 5)$ \\
Total & 391 & & 341 & \\
\hline
\end{tabular}

$\chi^{2}=5 \cdot 87, \mathrm{df}=3, p=0 \cdot 1179$.

cases. These differences were not statistically significant. Information regarding smoking was unavailable for $20.5 \%$ of the study population. The proportion of smokers in both groups was similar ( $46.3 \%$ and $47 \cdot 8 \%$ respectively). A slightly greater proportion of cases were ex-smokers compared with controls; non-smokers were more frequent in the control group $(13.2 \%)$ than in cases $(10.0 \%)$. The distribution of smoking state, however, did not differ significantly ( $p=0.3891$ ).

The presence of ischaemic heart disease was analysed in greater detail as this was thought to be a possible confounder in the analysis (table 3 ). There was no significant difference between cases and controls in either the presence of ischaemic heart disease or in its distribution by severity of disease $(p=0 \cdot 1179)$.

Table 4 shows distribution of emphysema, silicosis, and thromboembolic disease. There was a striking difference in the distribution of emphysema between cases and controls $\chi^{2}=73.35$, $\mathrm{p}<0.0001)$. The proportion of cases with marked or moderate emphysema $(53.2 \%)$ was more than twice that for controls $(25 \cdot 2 \%)$. The difference was even greater for the category of marked emphysema alone $(9 \cdot 2 \%$ of cases $v 0.6 \%$ of controls).

Both silicosis and emphysema were more preva-

Table 4 Distribution of emphysema, silicosis, and thromboembolic disease in the study population

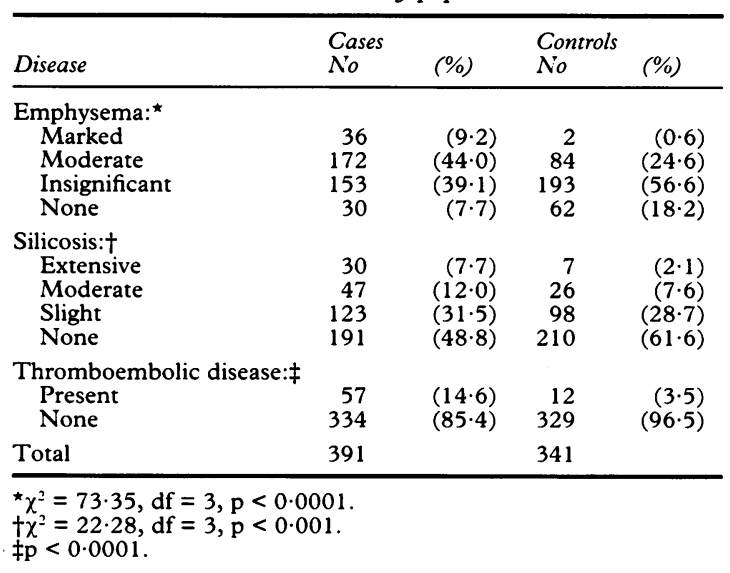

lent and severe in cases than in controls. Extensive silicotic disease was present in $7 \cdot 7 \%$ of cases and only $2 \cdot 1 \%$ of controls. Thromboembolic disease was four times more prevalent in cases $(14.6 \%)$ than in the control group (3.5\%). Thus it seems that emphysema, silicosis, and thromboembolic disease are highly associated with cor pulmonale at death.

The PC SAS CAT mode procedure was used in the regression analysis to determine the predictors of cor pulmonale. Fulton's ratio was used as the dependent variable in the model. Age at death, smoking state, presence of thromboembolic disease, and severity of emphysema and silicosis were the independent variables. "No emphysema" was included in the insignificant category to compensate for the small numbers.

Age and smoking did not contribute significantly to the model. Emphysema, silicosis, and thromboembolic disease were strong predictors of cor pulmonale (table 5). There was a 1.92 times greater risk of cor pulmonale with thromboembolism; a 2.77 times greater risk with moderate $v$ insignificant emphysema; and a strikingly increased risk of 21.32 with marked $v$ insignificant emphysema.

A statistically significant association between silicosis and cor pulmonale was found with extensive silicotic disease (odds ratio 4.95; $p=0.0003$ ). An odds ratio of 1.63 for moderate silicosis was calculated but this was only marginally significant $(p=0.0883)$. The odds ratio of 1.46 associated with slight silicosis was lower than that for moderate silicosis $(1.63)$ but was statistically significant $(\mathrm{p}=0.0338)$.

\section{Discussion}

This study has shown a statistically significant association between silicosis and cor pulmonale. Extensive silicosis was present in $7 \cdot 7 \%$ of cases and $2.1 \%$ of controls, moderate silicosis in $12 \%$ and $7 \cdot 6 \%$, and slight silicosis in $31.5 \%$ and $28.7 \%$ of cases and controls respectively (table 4 ). The difference in distribution of silicosis between cases and controls was statistically significant $\left(\chi^{2}=22 \cdot 28\right.$; $\mathrm{p}<0.001)$.

Table 5 Odds ratios for the predictors of cor pulmonale

\begin{tabular}{lrrr}
\hline Disease & $\begin{array}{c}\text { Odds } \\
\text { ratio }\end{array}$ & $95 \%$ CI & $p$ Value \\
\hline Emphysema: & & & \\
$\quad$ Marked : insignificant & 21.32 & $5.02-90.70$ & 0.0011 \\
$\quad$ Moderate : insignificant & 2.77 & $1.99-3.87$ & 0.0011 \\
$\quad$ Silicosis: & & & \\
$\quad$ Extensive : none & 4.95 & $2.92-8.38$ & 0.0003 \\
$\quad$ Moderate : none & 1.63 & $0.93-2.84$ & 0.0883 \\
$\quad$ Slight : none & 1.46 & $1.03-2.08$ & 0.0338 \\
Thromboembolic disease: & & & \\
$\quad$ Yes: no & 1.92 & $1.37-2.69$ & 0.0001 \\
\hline
\end{tabular}


Although standard textbooks ${ }^{12}$ and recent review articles $^{1314}$ associate silicosis with the development of cor pulmonale, there are little supporting data available. The results of the regression analysis of this study show a clear gradient of odds ratios corresponding to the severity of silicosis from slight to extensive grades of the disease.

Mortality studies have shown a slight increase in deaths due to heart disease among miners exposed to silica but cor pulmonale was not a subject of these studies..$^{1516}$ Other studies ${ }^{171920}$ of the relation between silicosis and cor pulmonale have been limited by virtue of the few cases and flawed by poor epidemiological and statistical methods. Methods of assessing right ventricular hypertrophy have not been reliable. The only accurate method for assessing right ventricular hypertrophy ${ }^{121}$ requires dissection of the heart according to Fulton's technique, ${ }^{9}$ a time consuming procedure that is rarely undertaken.

The data presented also show an association between emphysema and cor pulmonale. Marked emphysema was present in $9.2 \%$ of cases and $0.6 \%$ of controls (table 4) with an OR of 21.32 $(\mathrm{p}=0.0011)$ and moderate emphysema in $44 \%$ of cases and $24 \cdot 6 \%$ controls (OR 2.77, p $=0.0011$ ). Studies concerning the association between emphysema and cor pulmonale in the general population have given conflicting results. Some investigations have implicated the extent ${ }^{22}$ or the type ${ }^{2324}$ of emphysema in the development of cor pulmonale whereas other studies 2526 have failed to confirm a relation between emphysema and cor pulmonale.

In gold miners, emphysema occurs independent of pneumoconiotic changes. Several epidemiological studies have shown that exposure to silica dust, independent of the presence or severity of silicosis, is a risk factor for the development of emphysema. ${ }^{20-28}$ The risk of developing emphysema is more strongly associated with cigarette smoking than with exposure to dust; exposure to silica dust, in the absence of cigarette smoking, is associated only with insignificant and not moderate or marked emphysema. ${ }^{28}$ It is likely that exposure to dust plays a part in the development of cor pulmonale. Detailed information was unfortunately not available for this study and the causative role of exposure to dust will have to be considered in another study.

\section{POTENTIAL SOURCES OF BIAS}

Pack-years of smoking history were unavailable and subjects were crudely grouped according to smoking state, which was also unavailable for $20.5 \%$ of the study population.

The presence of cor pulmonale in some subjects with only insignificant emphysema as well as in subjects without silicosis suggests that airways dis- ease (chronic bronchitis and bronchiolitis) may also play a part. Numerous reports have documented the importance of peripheral airway narrowing in the development of right ventricular hypertrophy. ${ }^{2325}$ These data, however, were unavailable for this study.

Ischaemic heart disease is so prevalent that using it as an exclusion criterion would have resulted in an inadequate number of subjects for analysis. The proportion of cases with ischaemic heart disease was, however, similar to that of controls.

In conclusion, this study has provided evidence for the association of silicosis with the development of cor pulmonale, a theory that has lacked substantiating evidence in previous studies. Not only has the presence of silicosis been shown to be a risk factor for cor pulmonale in gold miners, but the risk increases with the severity of silicosis (from slight to extensive disease).

1 World Health Organisation. Chronic cor pulmonale: report of an expert committee. Circulation 1963;27:594-615.

2 Fishman AP. Pulmonary hypertension and cor pulmonale. In: Fishman AP, ed. Pulmonary diseases and disorders, 2nd ed. New York: McGraw-Hill International Book Company, 1988:999-1048.

3 Palevsky HI, Fishman AP. Chronic cor pulmonale: etiology and management. $\mathcal{F} A M A$ 1990;263:2347-53.

4 US Department of Health and Human Services. The health consequences of smoking: chronic obstructive lung disease. $A$ report of the Surgeon General. Rockville, Maryland: US Department of Health and Human Services, Public Health Service, Office on Smoking and Health, 1984:1-515. (DHHS (PHS) 84-50205.)

5 Becklake MR. Chronic airflow limitation: its relationship to work in dusty occupations. Chest 1985;88:608-14.

6 Webster I. Some aspects of the pathology of silicosis found in miners from the South African gold mines. In: Orenstein AJ, ed. Proceedings of pneumoconiosis conference, Fohannesburg 1959. London: Churchill, 1960:157-71.

7 Goldstein B, Webster I. The obligations of medical practitioners in relation to the new Mines and Works Act. $S$ Afr Med $\mathcal{F}$ 1976;50:975-7.

8 Hessel PA, Goldstein B, Davies JCA, Webster I, Hnizdo E, Landau S. Pathological findings in mine workers. I: description of the PATHAUT database. $A m$ f Ind Med 1987;12:71-80.

9 Fulton RM, Hutchinson EC, Morgan Jones A. Ventricular weight in cardiac hypertrophy. Br Heart f 1952;14:413-20.

10 Becklake MR, Irwig L, Kielkowski D, Webster I, De Beer M, Landau S. The predictors of emphysema in South African gold miners. Am Rev Respir Dis 1987;135:1234-41.

11 Gough J, Wentworth JE. Thin sections of entire organs mounted on paper. Harvey Lect (1957-58) 1959;53:182-5.

12 Parkes WR. Occupational lung disorders. Stoneham, Massachusetts: Butterworths, 1982:156.

13 Naye RL. Heart disease, cor pulmonale. In: Merchant JA, ed. Occupational respiratory diseases. Cincinnati: National Institute for Occupational Safety and Health, 1986:719-36.

14 Silicosis and silicate disease committee, National Institute for Occupational Safety and Health: Diseases associated with exposure to silica and nonfibrous silicate minerals. Arch Pathol Lab Med 1988;112:673-720.

15 McDonald JC, Gibbs GW, Liddell FDK, McDonald AD Mortality after long exposure to Cummingtonite-Grunerite. Am Rev Respir Dis 1978;118:271-7.

16 Wyndham CH, Bezuidenhout BN, Greenacre MJ, SluisCremer GK. Mortality of middle aged white South African gold miners. Br F Ind Med 1986;43:677-84.

17 Mack I, Snider GL. Respiratory insufficiency and chronic cor pulmonale. Circulation 1956;13:419--47.

18 Becker BJP, Chatgidakis CB. The heart in silicosis. In: Orenstein AJ, ed. Proceedings of pneumoconiosis conference, fohannesburg 1959. London: Churchill, 1960:205-16. 
19 Chatgidakis CB. A study of the state of the heart in the white South African gold miner. Medical Proceedings 1964;10: 132-8.

20 Smidt U, Schnellbacher F. Right ventricular hypertrophy, verified by autopsy, and symptoms of its development in patients with silicosis and coalworkers' pneumoconiosis Prax Pneumol 1978;32:407-16.

21 Hangartner JRW, Marley NJ, Whitehead A, Thomas AC, Davies MJ. The assessment of cardiac hypertrophy at autopsy. Histopathology 1985;9:1295-306.

22 Thurlbeck WM. A clinco-pathological study of emphysema in an American hospital. Thorax 1963;18:59-67.

23 Sweet HC, Wyatt JP, Fritsch AJ, Kinsella PW. Panlobular and centrilobular emphysema. Correlation of clinical findings with pathologic patterns. Ann Intern Med 1961;55:565-81.

24 Dunnill MS. An assessment of the anatomical factor in cor pulmonale in emphysema. $\mathcal{F}$ Clin Pathol 1961;14:246-58.
25 Jamal K, Fleetham JA, Thurlbeck WM. Cor pulmonale: correlation with central airway lesions, peripheral airway lesions, emphysema, and control of breathing. Am Rev Respir Dis 1990;141:1172-7.

26 Cromie JB. Correlation of anatomic pulmonary emphysema and right ventricular hypertrophy. $A m$ Rev Respir $D_{i s}$ $1961 ; 84: 657-62$.

27 Prinsloo J, Laubscher NF. Emphysema in South African gold miners. In: Shapiro HA, ed. Pneumoconiosis. Proceedings of the international conference, fohannesburg 1969. Cape Town Oxford University Press, 1970:380-5.

28 Hnizdo E, Sluis-Cremer GK, Abramowitz JA. Emphysema type in relation to silica dust exposure in South African gold miners. Am Rev Respir Dis 1991;143:1241-7.

Accepted 3 August 1992 